
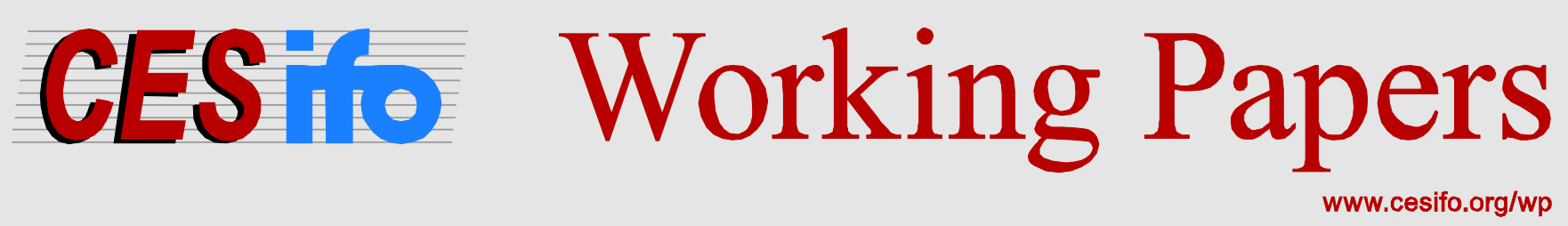

\title{
Robust Policies against Emission Leakage: The Case for Upstream Subsidies
}

\author{
Carolyn Fischer \\ Mads Greaker \\ Knut Einar Rosendahl
}
CESIFO WORKING PAPER NO. 4742
CATEGORY 10: ENERGY AND ClimATE ECONOMICS
APRIL 2014

An electronic version of the paper may be downloaded

- from the SSRN website:

- from the RePEc website:

- from the CESifo website:

WWW.SSRN.com

www.RePEc.org

www.CESifo-group.org/wp

\section{CESifo}




\title{
Robust Policies against Emission Leakage: The Case for Upstream Subsidies
}

\begin{abstract}
Asymmetric regulation of a global pollutant between countries can alter the competitiveness of industries and lead to emissions leakage, which hampers countries' welfare. In order to limit leakage, governments consider supporting domestic trade exposed firms by subsidizing their investments in abatement technology. The suppliers of such technologies tend to be less than perfectly competitive, particularly when both emissions regulations and advanced technologies are new. In this context of twin market failures, we consider the relative effects and desirability of subsidies for abatement technology. We find a more robust recommendation for upstream subsidies than for downstream subsidies. Downstream subsidies tend to increase global abatement technology prices, reduce pollution abatement abroad and increase emission leakage. On the contrary, upstream subsidies reduce abatement technology prices, and hence also emissions leakage. Moreover, as opposed to downstream subsidies, they provide domestic abatement technology firms with a strategic advantage.
\end{abstract}

JEL-Code: Q540, Q550.

Keywords: strategic environmental policy, carbon leakage, abatement technology.

\author{
Carolyn Fischer \\ Resources for the Future \\ Washington, D.C. 20036 / USA \\ fischer@rff.org
}

\author{
Mads Greaker \\ Statistics Norway \\ 0033 Oslo / Norway \\ mgr@ssb.no
}

\author{
Knut Einar Rosendahl \\ Norwegian University of Life Sciences \\ 1432 Ås / Norway \\ knut.einar.rosendahl@umb.no
}

6 February 2014

We thank the Norwegian Research Council for financial support. While carrying out this research, we have been associated with CREE - Oslo Center for Research on Environmentally friendly Energy. 


\section{Introduction}

Addressing the problem of a global pollutant is challenging, and made more so when regulatory regimes differ across jurisdictions. The prime example is the reduction of greenhouse gas (GHG) emissions. The United Nations Framework Convention on Climate Change (UNFCCC) explicitly states that countries have common but differentiated responsibilities (CBDR), putting greater regulatory burdens on developed than developing countries. This differentiation was made explicit in the Kyoto protocol, which divided countries into those with binding emissions limits (Annex I) and those without (Non-Annex I). At the meeting among the parties to the UNFCCC in Copenhagen in December 2009, countries agreed to set GHG mitigation targets, but targets were to be voluntary, and the stringency of the targets will not be harmonized. Differentiated responsibilities between developed and developing countries is also a part of the Montreal Protocol on substances that deplete the ozone layer.

In the case of a global pollutant, marginal abatement costs should ideally be equalized across countries, in order to allocate abatement effort efficiency. For several reasons - like CBDR - this rule may not be implemented, but asymmetry in regulation between countries can then create problems beyond an inefficient allocation of abatement resources. Unilateral increases in the stringency of regulation can alter the competitiveness of industries and lead to emissions leakage. Emissions leakage occurs whenever efforts by one country to reduce emissions leads to increased emissions in other countries. The welfare costs of meeting targets of environmental protection are then increased both globally and in the country with a more stringent environmental policy.

From the literature it is well known that emissions leakage can be partly counteracted by trade policy e.g. a combination of tariffs and export subsidies (Hoel 1996; Mæstad 1998; and 
Mæstad 2001). However, it remains unclear whether attempts to regulate production processes in other countries (such as with embodied carbon tariffs) would be found in accordance with WTO rules; see for instance Greaker (2006) or Fischer and Fox (2012). For most types of pollution, abatement technologies are available for firms to produce with lower emissions. Hence, governments may aid trade-exposed firms by subsidizing their abatement investments. According to the WTO, supporting the deployment and diffusion of green technologies is not hindered by WTO rules (WTO 2011).

In this paper we ask whether subsidies to pollution abatement technology should be used to limit emission leakage. We look at the question both from a global social planner perspective, and from a single region perspective. Moreover, we take into account that, according to recent studies cited in (among others) Requate (2005) and David and Sinclair-Desgagné (2010), the supply of abatement technology takes place in separate abatement technology firms. Our research question is therefore not only to what extent abatement subsidies should be used to limit emissions leakage, but also whether abatement subsidies should be given upstream or downstream.

Although subsidies to pollution abatement have long been proposed as a measure to limit emissions (Lerner 1972; Fredrikson 1998), to our knowledge, abatement subsidies have not been analyzed before as a countermeasure towards emissions leakage. We take downstream support policies to include all kinds of subsidies to the use of abatement technologies by polluting firms. Examples of technologies may be more efficient ironmaking processes, alternative aluminum smelting technologies, improved catalyst technologies, and carbon capture technologies for industries such as cement, refineries and steel.

Upstream policies comprise all types of support to upstream firms supplying abatement technologies. The number of firms supplying a particular abatement technology may be small, especially 
if the environmental problem in question is relatively new, such that the available abatement technologies are still under patent protection. The subsidies could be direct production subsidies or indirect subsidies to crucial inputs, such as R\&D or production capital. While such subsidies are offered in many countries, to our knowledge, they are not advocated as a countermeasure towards leakage.

Our findings suggest that one can make a more robust recommendation for upstream subsidies than downstream subsidies. With respect to domestic welfare, downstream subsidies tend to increase global abatement technology prices, reducing pollution abatement abroad, and likely increasing emissions leakage. Moreover, they do not provide domestic abatement technology firms with a strategic advantage and increase oligopoly profits abroad. On the contrary, upstream subsidies reduce abatement technology prices, and hence also emissions leakage. Furthermore, they shift oligopoly rents home, as they provide domestic abatement technology firms with a strategic advantage. Upstream subsidies are also likely to improve global welfare, as they reduce abatement technology prices and decrease global emissions.

Current policy, by contrast, seems to favor downstream subsidies. One example is the French tax on air pollution, where tax revenues are used to support investment in abatement technologies, particularly in industrial sectors (Millock and Nauges, 2006). Similarly, in Norway the government has established separate public funds financing both NOx and GHG abatement technology investment in industries. Finally, cap-and-trade with output-based allocation of quotas, which is the dominant allocation mechanism in the EU Emissions Trading System (ETS) from 2013, is also a subsidy to polluting firms, and will indirectly boost domestic investments in low-carbon technologies (see e.g. Rosendahl and Storrøsten, 2011). Thus, our finding that upstream subsidies are more robust than downstream subsidies when we have emissions leakage is a key takeaway of the paper. 
The result that upstream subsidies improve the environmental performance of foreign industries, hence limiting leakage, has some resemblance to Golombek and Hoel (2004). They found that R\&D investments in industrialized countries may reduce emissions in developing countries if there are technology spillovers that reduce developing countries' abatement costs. We find the same effect without assuming R\&D spillovers. Simply supporting the upstream abatement technology firm in one country will, through international trade in abatement technology, reduce the emissions intensity in other countries.

Our paper also has many similarities with Greaker and Rosendahl (2008). They found that it could be optimal for a single country to impose an excessively stringent environmental policy in order to reduce the mark-up of technology suppliers, and hence increase the diffusion of these technologies. In this study the upstream subsidy plays a similar role. Strategic effects with regards to the competition between domestic and foreign upstream suppliers were less important in Greaker and Rosendahl (2008). From a regional perspective, however, that could constitute an important aspect of an upstream support policy.

As mentioned, there are many studies of the use of trade measures to counteract emissions leakage. In addition to this strand of literature, Demailly and Quirion (2012) look at emissions permit allocation schemes as a measure to limit emissions leakage. In a numerical simulation of the European cement industry under the EU ETS, they find that output-based allocation of emissions permits may significantly limit leakage, as opposed to grandfathering (lump-sum allocations). As mentioned above, however, output based allocation will also likely boost the demand for abatement equipment, and hence may imply higher prices on such equipment. That could reduce pollution abatement in other regions, however, Demailly and Quirion (2012) do not include such mechanisms.

We begin by presenting the model and the different effects of upstream and downstream sub- 
sidies. Then we compare two cases. First, we look at the case in which Region 1 considers its own welfare (accounting for global emissions), and sets technology policy strategically. Then, we consider the case where subsidies in Region 1 are set in order to maximize global welfare.

\section{The model}

The world is divided into two regions, one domestic region (Region 1) and one foreign region (Region 2). In each region there is a "sunset" and a "sunrise" industry; the former producing some traditional industrial product, and the latter a new pollution abatement technology. Production of the industrial product leads to emissions of some pollutant that have cross-border damages (e.g. GHG emissions). In this downstream market, competition is perfect, and there are no barriers to trade. The upstream market producing the abatement technology also trades globally, but competition is imperfect. For simplicity, we assume that there is one firm located and owned in each of the two regions; in the numerical example we relax this assumption.

The game proceeds in a context in which each region has adopted a tax on emissions $t_{i}$, equal to its private valuation of the social cost of emissions; thus, neither internalizes emission damages in the other region. For ease of discourse, we generally assume $t_{1}>t_{2}>0$. In the first stage of the game, the government in Region 1 decides upon and announces its abatement technology policy, given the technology policy in the other region. We consider two different types of environmental technology policy: The government can subsidize abatement expenditures by the downstream firms, and it can subsidize the costs of the upstream technology firms. ${ }^{1}$

In the second stage of the game, the technology firms compete in Cournot fashion to supply abatement technology to the downstream industries in both countries. Cournot competition is cho-

\footnotetext{
${ }^{1}$ We assume that even if a region consists of many countries, for instance like the EU, it is able to coordinate its abatement technology policies.
} 
sen because we believe that firms supplying a particular type of patented equipment first determine production capacity and then decide on the price.

\subsection{The downstream market equilibrium}

First, we need to solve for the downstream market equilibrium and derive the implicit demand functions for abatement technology in each region. This task is not trivial, since the emission tax affects both the output of the downstream industries and their demand for abatement equipment. In order to highlight the leakage issue, we assume that total global demand for the downstream product is fixed at $Q$; in the conclusions we discuss the implications of relaxing this assumption.

We describe a stylized downstream industry inspired by Laffont and Tirole (1996). Let there be $S$ production lines in each region, and each line has unit production. With $S>Q$, each region could in theory serve the entire global market; however, production costs along the line are heterogeneous, leading to upward-sloping supply curves in each region. Let the cost of a production line be uniformly distributed on $[0, S]$, reflecting different degrees of efficiency of input use, such as may arise from different capital vintages. Denote by $q_{i} \in[0, Q]$ the number of lines producing $(=$ production); then the sum of production $\operatorname{costs} c_{i}$ in the regional industry as a whole are quadratic: $c_{i}\left(q_{i}\right)=q_{i}^{2} / 2$.

Gross emissions from each production line are assumed to be proportional to costs; in other words, firms with high costs use inputs - like energy — inefficiently and thus also have high emissions. Let regional gross emissions thus be $E_{i}=\left(q_{i}\right)^{2} / 2$. However, an end-of-pipe abatement technology exists that reduces emissions from a production line, independent of the vintage, down to that of the best performer (in this case 1/2, the emissions of the first firm in the distribution). This technology is supplied by imperfectly competitive firms for a price $w$, but part of that cost may be 
offset by a subsidy $\eta_{i}$ from the government to each buyer of abatement equipment. Given the cost of installation, the most polluting lines will install abatement technology first. Denote by $x_{i}$ the number of lines that install the abatement technology in region $i$; emissions from these lines will then be $x_{i} / 2$. The firms not installing the abatement technology will be distributed on $\left[0,\left(q_{i}-x_{i}\right)\right]$, and their emissions will total $\left(q_{i}-x_{i}\right)^{2} / 2$. Thus, regional net emissions are $e_{i}=\left(\left(q_{i}-x_{i}\right)^{2}+x_{i}\right) / 2$.

Downstream firms are perfectly competitive, and their abatement decisions are made to minimize their compliance costs: emissions tax payments plus technology costs. For the production line in region $i$ that is just indifferent to adopting the abatement technology, we have $t_{i}\left(q_{i}-x_{i}-1 / 2\right)=$ $t_{i} / 2+w-\eta_{i}{ }^{2}$ or

$$
x_{i}=q_{i}-\frac{t_{i}+w-\eta_{i}}{t_{i}}
$$

Thus, the equilibrium level of emissions is

$$
e_{i}=\frac{1}{2}\left(\left(\frac{t_{i}+w-\eta_{i}}{t_{i}}\right)^{2}+q_{i}-\frac{t_{i}+w-\eta_{i}}{t_{i}}\right)=\frac{1}{2}\left(q_{i}+\frac{\left(w-\eta_{i}\right)\left(t_{i}+w-\eta_{i}\right)}{t_{i}^{2}}\right)
$$

and total costs of regional supply, $C_{i}$, inclusive of not only production $\operatorname{costs} c_{i}$ but also emissions payments and abatement equipment purchases, are

$$
C_{i}=\frac{q_{i}^{2}}{2}+\frac{t_{i}}{2}\left(q_{i}+\frac{\left(w-\eta_{i}\right)\left(t_{i}+w-\eta_{i}\right)}{t_{i}^{2}}\right)+\left(w-\eta_{i}\right)\left(q_{i}-\frac{t_{i}+w-\eta_{i}}{t_{i}}\right)
$$

In reduced form, this cost function can be written as

\footnotetext{
${ }^{2}$ The incremental emissions of the last non-adopter are $\int_{q_{i}-x_{i}-1}^{q_{i}-x_{i}} z d z=q_{i}-x_{i}-1 / 2$.
} 


$$
C_{i}=\frac{q_{i}^{2}}{2}+\left[\frac{t_{i}}{2}+w-\eta_{i}\right] q_{i}+f_{i}
$$

where $f_{i}=-\left(w-\eta_{i}\right)\left(t_{i}+w-\eta_{i}\right) /\left(2 t_{i}\right)$ is a fixed cost. ${ }^{3}$ From (3) we note that the supply curve of each industry is upward sloping and linear. Furthermore, a higher regional tax shifts the supply curve vertically upwards, while a regional abatement subsidy shifts the curve vertically downwards.

In equilibrium the marginal cost of the two industries must be equal to the downstream price $P$; that is, $P=q_{1}+t_{1} / 2+w-\eta_{1}=q_{2}+t_{2} / 2+w-\eta_{2}$. Adding these two regional price equations, and using the fact that global supply must equal global demand $\left(q_{1}+q_{2}=Q\right)$, we find the reduced form downstream market price is given by:

$$
P=\frac{Q+\left(t_{2}+t_{1}\right) / 2+2 w-\eta_{1}-\eta_{2}}{2}
$$

Substituting, we derive the equilibrium supply of the industry in region $i$ :

$$
q_{i}=\frac{Q+\left(t_{j}-t_{i}\right) / 2+\eta_{i}-\eta_{j}}{2}
$$

Note that for equal subsidy rates $\left(\eta_{i}=\eta_{j}\right)$, the industry with the lower emissions tax rate will have a higher market share. From a global point of view, this result is not optimal since the two industries have identical production costs and emission abatement opportunities. Thus, the asymmetric regulation of the global pollutant yields a non-optimal allocation of world production, which results in both too high production costs and emissions. On the other hand, since $\partial q_{i} / \partial \eta_{i}>0$ and $\partial q_{j} / \partial \eta_{i}<0$, unequal subsidy rates may restore the optimal allocation of production. However, be-

\footnotetext{
${ }^{3}$ See the Appendix for a complete derivation of the reduced form cost function.
} 
fore we look at the desirability of an abatement technology subsidy, we must solve for the upstream market equilibrium.

\subsection{The upstream market equilibrium}

Global demand for abatement technology is the sum of the two regional demands, i.e., $x_{1}+x_{2}$. Using (1) and (5), and inverting the resulting abatement technology demand function, we obtain the inverse demand curve for the upstream suppliers:

$$
w=\frac{t_{1} t_{2}}{t_{1}+t_{2}}\left(Q+\frac{\eta_{1}}{t_{1}}+\frac{\eta_{2}}{t_{2}}-2-x_{1}-x_{2}\right)
$$

Note that (6) is a downward sloping, linear demand curve, which makes solving for the Cournot equilibrium upstream straightforward.

Denote the supply of abatement technology from the firm in region $i$ by $y_{i}$. Let both firms have constant unit costs $\rho-\gamma_{i}$, where $\gamma_{i}$ denotes the upstream technology subsidy. This subsidy may come in the form of direct subsidies, tax breaks, or even R\&D support - essentially, anything that lowers marginal production costs. Total abatement will be the result of a Cournot game, recognizing that in equilibrium $y_{1}+y_{2}=x_{1}+x_{2}$. Both firms maximize profits: $\left[w-\rho+\gamma_{i}\right] y_{i}$. From the first-order conditions we obtain the following Nash-equilibrium outputs and price on abatement technology (see the Appendix for derivations):

$$
\begin{gathered}
y_{i}=\frac{Q-2}{3}+\frac{\eta_{i}}{3 t_{i}}+\frac{\eta_{j}}{3 t_{j}}+\left(2 \gamma_{i}-\gamma_{j}-\rho\right) \frac{t_{i}+t_{j}}{3 t_{i} t_{j}} \\
w=\frac{t_{1} t_{2}}{t_{1}+t_{2}}\left(\frac{Q-2}{3}+\frac{\eta_{1}}{3 t_{1}}+\frac{\eta_{2}}{3 t_{2}}\right)-\frac{\gamma_{1}+\gamma_{2}-2 \rho}{3}
\end{gathered}
$$


The technology policy measures have different effects on the upstream and the downstream markets and also on emission leakage. In the next section we summarize these results before looking at the optimal use of the technology measures.

\section{$3 \quad$ Effects of the technology policy measures}

\subsection{Upstream}

The first proposition is about the effects on the upstream price of abatement equipment:

Proposition 1 The market price of abatement equipment $w$ increases if one of the regions increases the downstream subsidy $\eta_{i}$, while the market price decreases if one of the regions increases the upstream subsidy $\gamma_{i}$.

Proof. The results can be seen directly from (8).

The intuition behind the result is that increasing the subsidizing of abatement investments in Region 1 makes demand for abatement less price elastic. The upstream technology firms responds by increasing their price-cost margin. By contrast, the upstream subsidy does not shift the demand function, and hence the decreased cost of making abatement equipment is transferred partly to the downstream firms.

The second proposition is about the effects upon abatement supply:

Proposition 2 If one of the regions increases the downstream subsidy rate $\eta_{i}$, both upstream firms will increase their supply of abatement equipment $y_{i}$. If one of the regions increases its upstream subsidy rate $\gamma_{i}, y_{i}$ increases, $y_{j}$ decreases, and total supply of abatement equipment increases.

Proof. See (7). 
Proposition 2 is important for the regional welfare effects of the two subsidies. While a downstream subsidy promotes both foreign and domestic abatement technology suppliers, the upstream subsidy promotes only domestic suppliers.

\subsection{Downstream}

We now turn to the downstream market equilibrium effects of a change in $\eta_{1}$. We can then show the following proposition:

Proposition 3 If Region $i$ increases its downstream subsidy rate $\eta_{i}$, the price $P$ decreases. Moreover, the downstream firm in Region $i$ increases its output and use of abatement equipment, while the downstream firm in Region $j$ decreases its output and use of abatement equipment.

Proof. By differentiating (4) we have $\frac{d P}{d \eta_{i}}=-\frac{1}{2}+\frac{t_{j}}{3\left(t_{1}+t_{2}\right)}$. From (5) we have $\partial q_{i} / \partial \eta_{i}>0$, and $\partial q_{j} / \partial \eta_{i}<0$. Further, from (1) we then have $\partial x_{j} / \partial \eta_{i}<0$ since $\partial w / \partial \eta_{i}>0$. We must then have $\partial x_{i} / \partial \eta_{i}>0$ since total abatement supply increases.

Note that the foreign industry reduces its use of abatement both due to the increase in price and due to the reduced output.

Second, we consider the effects of the upstream subsidy:

Proposition 4 If Region $i$ increases its upstream subsidy rate $\gamma_{i}$, both downstream firms increase their use of abatement equipment. Moreover, the price $P$ decreases.

Proof. Note from (5) that $\partial q_{i} / \partial \gamma_{i}=\partial q_{j} / \partial \gamma_{i}=0$. We know that $\partial w / \partial \gamma_{i}<0$. The first part of the proposition then follows from (1). The last part follows from (4).

Proposition 3 and 4 are also important for the welfare effects of the two subsidies. While a downstream subsidy promotes only domestic use of abatement technology, the upstream subsidy 
promotes both domestic and foreign use.

\subsection{Emission leakage}

Emissions leakage occurs whenever efforts by one country to reduce emissions lead to increased emissions in other countries. Emissions in Region 2 are given by (2). First, note that a higher $t_{1}$ unambiguously leads to increased emissions in Region 2 as long as $\frac{d w}{d t_{1}}>0:^{4}$

$$
\frac{\partial e_{2}}{\partial t_{1}}=\frac{1}{8}+\frac{\left(t_{2} / 2+w-\eta_{2}\right)}{\left(t_{2}\right)^{2}} \frac{d w}{d t_{1}}>0
$$

where $\frac{d w}{d t_{1}}=\frac{\left(t_{2}\right)^{2}}{\left(t_{1}+t_{2}\right)^{2}}\left(\frac{Q-2}{3}+\frac{\eta_{2}-\eta_{1}}{3 t_{2}}\right)($ see 8$)$.

Emission leakage happens through two channels when $t_{1}$ rises. First, industrial output shifts toward the foreign region. Second, as demand for abatement equipment in Region 1 increases, the price of equipment rises, leading to less abatement by the foreign industry. Since we are looking at transboundary pollution, increased emissions from the other region reduces welfare in the region that increases its emission tax.

Our first research question is whether abatement subsidies can reduce this effect. We first look at the effects of increasing $\eta_{1}$ :

$$
\frac{\partial e_{2}}{\partial \eta_{1}}=\frac{\left(t_{2} / 2+w-\eta_{2}\right)}{3 t_{2}\left(t_{1}+t_{2}\right)}-\frac{1}{4}
$$

Proposition 5 A downstream subsidy in Region 1 will lead to lower emissions in Region 2 if and only if $w-\eta_{2}<\frac{1}{4} t_{2}\left(3 t_{1}+3 t_{2}-2\right)$.

Increasing the downstream subsidy has an ambiguous effect. On the one hand, output is re-

\footnotetext{
${ }^{4}$ Derivations of the effects on $e_{2}$ are found in the Appendix.
} 
located from the foreign to the home region. On the other hand, the subsidy increases the price on abatement equipment, which makes the foreign industry buy less equipment. Since $w$ depends crucially on the policy instruments, it is not straightforward to evaluate the sign of (10). However, the higher are the initial levels of $\gamma_{i}$ and $\eta_{2}$, and the lower is the initial level of $\eta_{1}$, the more likely it is that an increase in $\eta_{1}$ will mitigate leakage.

On the other hand, the effect of raising $\gamma_{1}$ is unambiguous:

$$
\frac{\partial e_{2}}{\partial \gamma_{1}}=-\frac{t_{2} / 2+w-\eta_{2}}{3\left(t_{2}\right)^{2}}<0
$$

Proposition 6 An upstream subsidy in Region 1 will lead to lower emissions in Region 2.

The two propositions above suggest that if the government must choose between upstream and downstream subsidies, the upstream subsidy is more robust with respect to reducing emission leakage.

We are now ready to consider welfare effects of technology policies in Region 1, taking into account the findings above.

\section{Strategic abatement technology policies}

We start by looking at the regional welfare perspective, which is presumably the objective of regional policymakers. Regional welfare includes its own surplus and production costs, as well as its own valuation of environmental costs due to global emissions. In addition, from the perspective of a region, revenues are not merely transfers between buyers and sellers to the extent that there are net imports, and regions can benefit from changes in the terms of trade (ToT).

Since downstream demand is fixed, gross consumer surplus in Region 1 is given. Let downstream 
consumption in Region 1 amount to a market share $\mu$ of total consumption. Assuming that Region 1 considers $t_{1}$ as the shadow cost of global emissions, the welfare for Region 1 can then be expressed in the following way:

$$
\begin{aligned}
W_{1}= & \Omega_{1}-\mu P\left(q_{1}+q_{2}\right)+P q_{1}-\frac{\left(q_{1}\right)^{2}}{2}-w x_{1} \\
& +(w-\rho) y_{1}-t_{1}\left(e_{1}+e_{2}\right)
\end{aligned}
$$

where $\Omega_{1}$ is gross consumer surplus in Region $1, P$ is the downstream market price, and $\mu$ is the share of consumption going to Region 1 . First, note that $P, q_{1}, q_{2}, x_{1}, w, y_{1}, e_{1}$ and $e_{2}$ are all functions of the policy variables $t_{i}, \eta_{i}$ and $\gamma_{i}$. In the analysis below we focus on the case where there are no subsidies in Region $2\left(\eta_{2}=\gamma_{2}=0\right)$. Second, note that emission taxes, downstream subsidies and upstream subsidies either paid or received by the firms and either received or paid by the government cancel out.

Technology policy has several aims: If Region 1 is a net importer of the final good, it would like $P$ to go down. The same holds for $w$ if Region 1 is a net importer of abatement technology. Further, Region 1 would like to shift oligopoly profit to its own upstream industry, and it would like more use of abatement technology at home due to the mark-up pricing. Finally, Region 1 would like emissions in Region 2 to decline.

In order to analyze to what extent Region 1 should use downstream or upstream or both types of subsidies, we differentiate $W_{1}$ wrt. $\eta_{1}$ and $\gamma_{1}$. Further, we evaluate the sign on derivative of the welfare function for $\eta_{1}$ and $\gamma_{1}$ close to zero. The derivative with respect to the downstream subsidy is given by: 


$$
\begin{aligned}
\frac{d W_{1}}{d \eta_{1}}=\underbrace{\left(q_{1}-\mu Q\right) \frac{d P}{d \eta_{1}}}_{\text {Downstream ToT }}+\underbrace{\left(y_{1}-x_{1}\right) \frac{d w}{d \eta_{1}}}_{\text {Upstream ToT }}+\underbrace{(w-\rho)\left(\frac{d y_{1}}{d \eta_{1}}-\frac{d x_{1}}{d \eta_{1}}\right)}_{\text {Net Export Changes }} \\
+\underbrace{\left(w+\frac{3}{2} t_{1}-\eta_{1}-\rho\right) \frac{d x_{1}}{d \eta_{1}}}_{\text {Domestic Abatement }}-\underbrace{\left(\frac{\left(t_{2} / 2+w\right)}{3 t_{2}\left(t_{1}+t_{2}\right)}\right)}_{\text {Leakage }} t_{1}
\end{aligned}
$$

The two first terms can be coined terms of trade effects. We know that $\frac{d P}{d \eta_{1}}<0$, and hence, the first term is positive if Region 1 is a net importer of the downstream good, which will be the case if $\mu=0.5$ and there are no subsidies (since $t_{2}<t_{1}$ ). The second term is negative if $\gamma_{1}=0$. Then $y_{1}=y_{2}$. As long as $t_{1}>t_{2}$ and $\eta_{1} \geq \eta_{2}$, we must have $x_{1}>x_{2}$, and hence, $y_{1}-x_{1}<0$. We know that $\frac{d w}{d \eta_{1}}>0$

The third term is the profit shifting effect. We can calculate $\frac{d y_{1}}{d \eta_{1}}-\frac{d x_{1}}{d \eta_{1}}=-\frac{1}{2}-\frac{2}{3 t_{1}}+\frac{1}{3\left(t_{1}+t_{2}\right)}<0$. Thus, profit is shifted abroad since domestic consumption of abatement technology increases more than domestic production. The fourth term is positive; the downstream subsidy increases the use of abatement equipment at home. The fifth term is negative as a downstream subsidy increases the price on abatement leading to less abatement being carried out in Region 2.

To sum up, we have one ambiguous effect (ToT downstream), one positive and three negative effects, and consequently we cannot say whether use of the downstream subsidy increases welfare.

The derivative with respect to the upstream subsidy is given by:: 


$$
\begin{aligned}
\frac{d W_{1}}{d \gamma_{1}}= & \underbrace{\left(q_{1}-\mu Q\right) \frac{d P}{d \gamma_{1}}}_{\text {Downstream ToT }}+\underbrace{\left(y_{1}-x_{1}\right) \frac{d w}{d \gamma_{1}}}_{\text {Upstream ToT }}+\underbrace{(w-\rho)\left(\frac{d y_{1}}{d \gamma_{1}}-\frac{d x_{1}}{d \gamma_{1}}\right)}_{\text {Net Export Changes }} \\
& +\underbrace{\left[w+\frac{3}{2} t_{1}-\eta_{1}-\rho\right] \frac{d x}{d \gamma_{1}}}_{\text {Domestic Abatement }}-\underbrace{t_{1} \frac{d e_{2}}{d \gamma_{1}}}_{\text {Leakage }}
\end{aligned}
$$

The first term in (14) has the same sign as the first term in (13): The upstream subsidy improves terms of trade downstream as long as Region 1 is a net importer. The upstream subsidy now also improves upstream terms of trade for $\gamma_{1}=0$, as we then have $x_{1}>y_{1}$ and $\frac{d w}{d \gamma_{1}}<0$.

Moreover, we have $\frac{d y_{1}}{d \gamma_{1}}-\frac{d x_{1}}{d \gamma_{1}}=\frac{2 t_{1}+t_{2}}{3 t_{1} t_{2}}$. Thus, profit is shifted home since domestic production of abatement technology increases more than domestic consumption. The fourth term is positive; the upstream subsidy increases the use of abatement equipment at home. Lastly, the fifth term is also positive since a upstream subsidy decreases emissions in Region 2. Thus, we have one ambiguous effect (ToT downstream) and four positive effects.

Proposition 7 For $q_{1} \leq \mu Q, t_{1} \geq t_{2}$ and $\eta_{1}=0$, it is optimal for Region 1 to implement a positive upstream subsidy.

Clearly, it may be optimal to implement a positive upstream subsidy even if $q_{1}>\mu Q$ as all the other terms in (14) are positive. By continuity, for $\gamma_{1}$ small, increasing the upstream subsidy improves terms of trade upstream, shifts oligopoly profits home, increases the use of abatement equipment at home and reduces emissions abroad. A downstream subsidy has the opposite effects on the terms of trade upstream, and ambiguous effect on emissions abroad. Hence, we find a more robust recommendation for upstream subsidies than for downstream subsidies. 


\section{Globally optimal abatement technology policies}

In the strategic trade literature - see for instance Brander and Spencer (1985) - supporting domestic firms is a kind of beggar-thy-neighbor policy. This need not be strictly the case when it comes to supporting pollution abatement technology, as long as emissions leakage is an issue. In order to discuss to what extent strategic policies hamper global welfare, we ask the hypothetical question: What kind of technology policy should Region 1 implement if it cares about global welfare?

Since downstream demand is fixed, gross consumer surplus is given. Maximizing global welfare thus implies minimizing the sum of production costs, abatement costs and emissions damages (denoted $T C$ ), where $t_{1}+t_{2}$ denotes the global shadow cost of emissions; revenues are simply transfers. The technology policy then has two aims: First, unequal tax rates in the two regions imply inefficient allocation of downstream production. Second, imperfect competition and too low tax rates in both regions imply too little use of abatement technology. We have:

$$
T C=\frac{\left(q_{1}\right)^{2}}{2}+\frac{\left(q_{2}\right)^{2}}{2}+\rho\left(x_{1}+x_{2}\right)+\left(t_{1}+t_{2}\right)\left(e_{1}+e_{2}\right)
$$

where the first two terms in (15) are downstream production costs in the two regions, the second term is upstream abatement technology costs in the two regions and the third term is total environmental damages. Again, all tax and subsidy payments cancel out.

In order to look at the effect of providing technology subsidies, we differentiate the social cost function $T C$ wrt. $\eta_{1}$ and $\gamma_{1}$. Further, we evaluate the sign on derivative of the cost function for $\eta_{1}$ and $\gamma_{1}$ close to zero. We focus on the case where there are no subsidies in Region $2\left(\eta_{2}=\gamma_{2}=0\right)$. The derivatives of $T C$ with respect to $\eta_{1}$ and $\gamma_{1}$ are given by (see the Appendix): 


$$
\begin{aligned}
\frac{d T C}{d \eta_{1}}= & \underbrace{\frac{t_{2}-t_{1}+2 \eta_{1}}{4}}_{\text {Production costs }}+\underbrace{\frac{t_{1}+t_{2}}{\left(t_{1}\right)^{2}}\left(w+\frac{t_{1}}{2}-\eta_{1}-\frac{t_{1}}{t_{1}+t_{2}} \rho\right)\left(\frac{d w}{d \eta_{1}}-1\right)}_{\text {Abatement Reg. 1 }} \\
& \underbrace{+\frac{t_{1}+t_{2}}{\left(t_{2}\right)^{2}}\left(w+\frac{t_{2}}{2}-\frac{t_{2}}{t_{1}+t_{2}} \rho\right) \frac{d w}{d \eta_{1}}}_{\text {Abatement Reg. } 2}
\end{aligned}
$$

$$
\frac{d T C}{d \gamma_{1}}=\underbrace{\frac{t_{1}+t_{2}}{\left(t_{1}\right)^{2}}\left(w+\frac{t_{1}}{2}-\eta_{1}-\frac{t_{1}}{t_{1}+t_{2}} \rho\right) \frac{d w}{d \gamma_{1}}}_{\text {Abatement Reg. } 1}+\underbrace{\frac{t_{1}+t_{2}}{\left(t_{2}\right)^{2}}\left(w+\frac{t_{2}}{2}-\frac{t_{2}}{t_{1}+t_{2}} \rho\right) \frac{d w}{d \gamma_{1}}}_{\text {Abatement Reg. } 2}
$$

The first term in (16) does not have a counterpart in (17) as only the downstream subsidy reallocates downstream production. Total production costs decrease as long as $q_{1}$ is smaller than $q_{2}$, since downstream production costs are minimized when $q_{1}=q_{2}$. Thus, with $\eta_{1}$ and $\gamma_{1}$ close to zero, the first term in (16) is negative. This is also the case for the second term in (16), but not for the last term which is positive. That is, the expressions $\left(w+\frac{t_{1}}{2}-\eta_{1}-\frac{t_{1}}{t_{1}+t_{2}} \rho\right)$ and $\left(w+\frac{t_{2}}{2}-\frac{t_{2}}{t_{1}+t_{2}} \rho\right)$ are positive since $w>\rho$ (e.g. there is a mark-up), while $\left(\frac{d w}{d \eta_{1}}-1\right)$ is negative and $\frac{d w}{d \eta_{1}}$ is positive. Due to the sign on the third term we cannot say whether use of the downstream subsidy decreases social costs.

In (17) both terms are negative as long as the expression $\left(w+\frac{t_{1}}{2}-\eta_{1}-\frac{t_{1}}{t_{1}+t_{2}} \rho\right)$ is positive. Note that it may become negative if $\eta_{1}$ is large. Thus, we have:

Proposition 8 As long as $\eta_{1}<w+\frac{t_{1}}{2}-\frac{t_{1}}{t_{1}+t_{2}} \rho$, global welfare improves if Region 1 implements a positive upstream subsidy.

Both subsidies increase the use of abatement equipment in Region 1; i.e., the second term in (16) and the first term in (17) are negative. But only the upstream subsidy can increase the use of 
abatement equipment abroad; i.e., the last term in (16) is positive.

In many cases it may be optimal to use both subsidies e.g. both $\eta_{1}$ and $\gamma_{1}$ are positive. The downstream subsidy then improves the allocation of downstream production, while the upstream subsidy deals with the insufficient use of abatement technology.

What happens to the welfare of Region 2 when Region 1 uses an upstream subsidy? Region 2 will benefit from lower global emissions and lower costs on abatement equipment. On the other hand, the upstream terms of trade effects pull in the other direction, leaving the total effect on the welfare of Region 2 ambiguous. Below we present a numerical example in which we compare globally optimal policies with strategic policies. We also look at the effect on Region 2 welfare.

\section{Numerical example}

In this numerical example, we consider the role of the degree of competition upstream by allowing for multiple upstream firms: $m$ firms operate in Region 1 and $n$ firms operate in Region 2 (see the Appendix for the Nash-Cournot solution upstream). In our baseline example, we let $Q=100$, $\mu=0.5, m+n=4, t_{1}=t_{2}=1$ and both types of subsidies in both regions are initially zero. The value of $\rho$ is calibrated so that $x_{i}=25$; i.e., half of the firms in each region buy abatement equipment, given the emissions tax (this gives $\rho=18$ ). We then introduce optimal subsides in Region 1 while keeping $\eta_{2}=\gamma_{2}=0$.

The optimal subsidies will depend on the difference in emissions tax levels, the configuration of upstream firms, and whether regional or global welfare is being maximized. In Figure 1, we have maximized the welfare of Region1, and drawn the optimal combination of subsidies, $\gamma_{1}$ and $\eta_{1}$. We have also looked at different configurations of the upstream firms, and at different values of $t_{2}$. The higher the upstream subsidy in Region 1, and the lower the emissions tax in Region 2, 
the more likely it is that the foreign abatement technology firms exit the market due to the high upstream subsidy in Region 1. Without any restrictions on the subsidies, the optimal upstream subsidy becomes very high under some configurations; thus, we set an upper limit on both subsidies equal to $\rho\left(\gamma_{1}, \eta_{1} \leq \rho\right)$.

Figure 1 "Optimal combination of subsidies for Region 1"

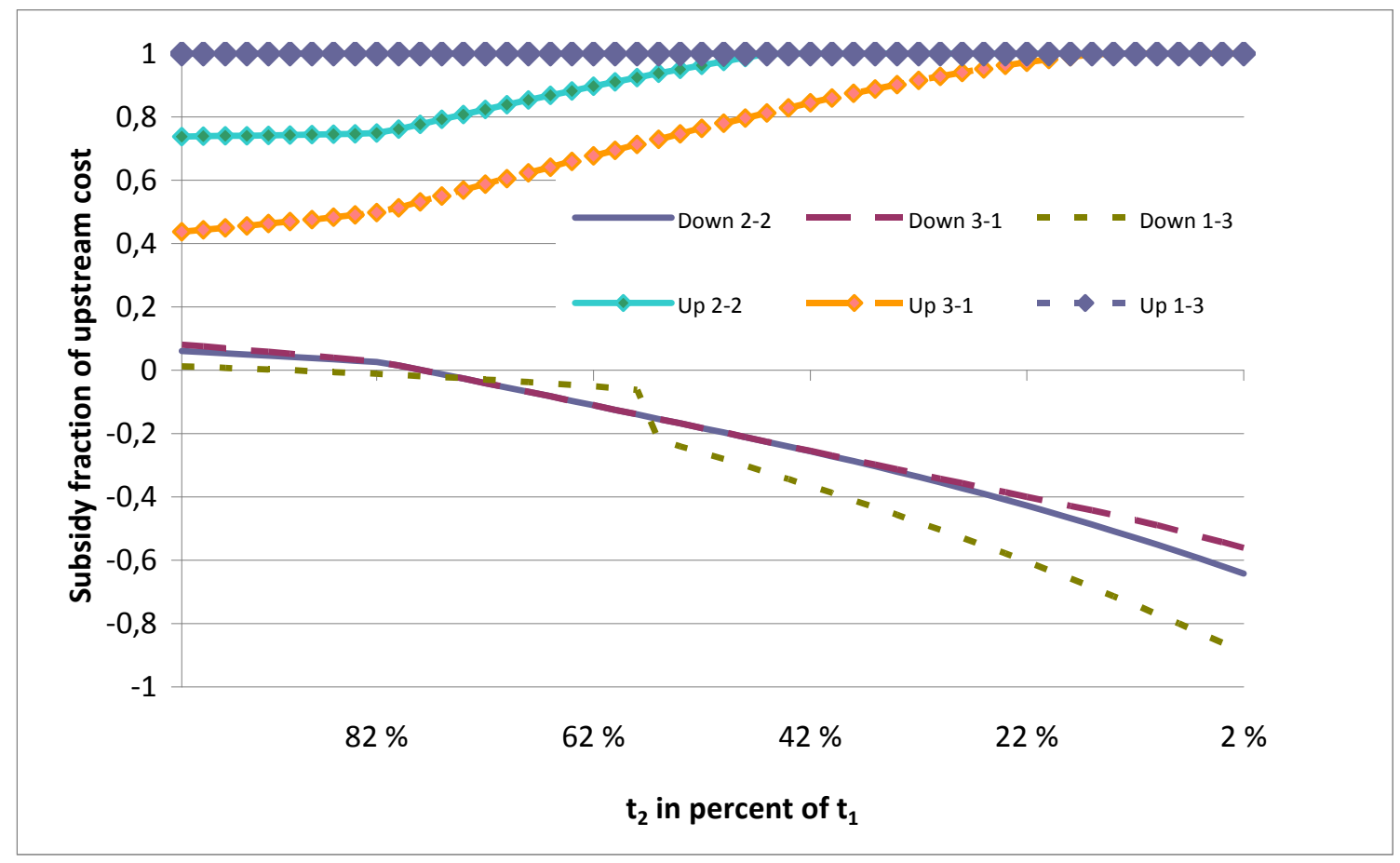

Along the y-axis we measure the subsidies relative to the cost of providing abatement equipment (in fraction of the upstream cost $\rho$ ), while we measure the value of $t_{2}$ in percent of $t_{1}$ on the x-axis. We show the results for three different configurations. For instance, "1-3" implies that there are 1 upstream firm in Region 1 and 3 upstream firms in Region 2. We see that the optimal upstream 
subsidy is always positive and significantly higher than the downstream subsidy. This remains the case even though some upstream firms drop out of the market in many situations (e.g., for $t_{2}<0.75 t_{1}$ for the configurations $2-2$ and $3-1$ ), in which case the profit shifting effect vanishes. Moreover, we find the corner solution of a $100 \%$ subsidy is optimal $\left(\gamma_{1}=\rho\right)$ for any $t_{2}$ with the configuration 1-3, and for low values of $t_{2}$ for the two other configurations. This confirms our main message in the paper that imposing upstream subsidies is a more robust technology policy choice from a strategic perspective.

Next, note that the optimal downstream subsidy $\eta_{1}$ declines the smaller is the foreign tax rate $t_{2}$. At first thought this seems counter-intuitive, since the emission leakage problem is more pronounced the higher is the difference in emission tax rates. However, the downstream subsidy on the margin exacerbates leakage more the lower is the tax rate abroad. Finally, note that the downstream subsidy is lowest if the upstream configuration is 1-3. The reason is that both the terms-of-trade effect and the profit shifting effect upstream is more negative in this case.

Why does Region 1 want to implement an upstream subsidy $\gamma_{1}$ which may be larger than the cost $\rho$ ? As long as the upstream price $\left(1-\eta_{1}\right) w$ is greater than the upstream cost $\rho$, there is too little use of abatement equipment in Region 1. Thus, when the downstream subsidy becomes low or even negative, we tend to get a very high upstream subsidy. In addition comes the beneficial effect from reduced emissions abroad which also drives the high upstream subsidy (see Figure 3).

In Figure 2 we look at the optimal subsidies with a global perspective. In this case we always get $\gamma_{1}=\rho$, and we have not drawn $\gamma_{1}$ for any of the configurations. Note that in the global welfare case, the use of abatement equipment is too low for two reasons: The emission tax in both regions falls short of marginal environmental damage $\left(t_{1}+t_{2}\right)$, and the upstream price is higher than the upstream cost. This holds in particular in Region 2 in which a downstream subsidy is not 
implemented.

Figure 2 "Globally optimal combinations of subsidies"

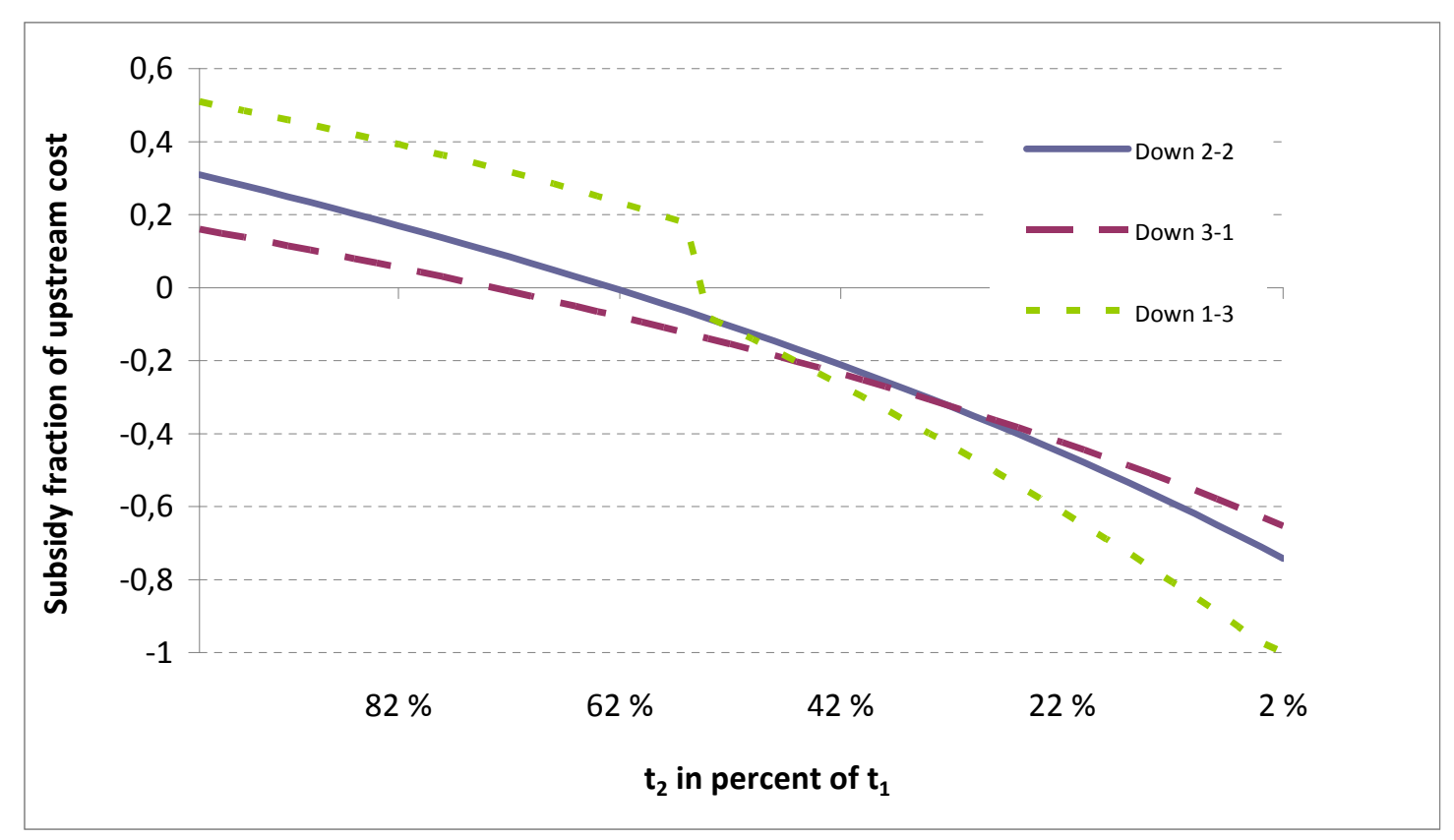

First, note that the downstream subsidy should be much higher in the global case than in the regional case. The reason is that from the global perspective, downstream production should be equally split between the regions, and only the downstream subsidy can accomplish that. As above, the optimal downstream subsidy $\eta_{1}$ declines the smaller is the foreign tax rate $t_{2}$. Again, the downstream subsidy on the margin increases emissions abroad more the lower is the tax rate abroad. Moreover, in our example this effect dominates the effect from the increased downstream production cost.

We have also looked at the effect on leakage with the 2-2 configuration of upstream firms. In 
Figure 2 the increase/reduction in foreign emissions is measured for different values of $t_{2}$. Here we consider one subsidy at a time, where the subsidy level is set to $0.25 \rho$.

Figure 3 "The effect on emission leakage"

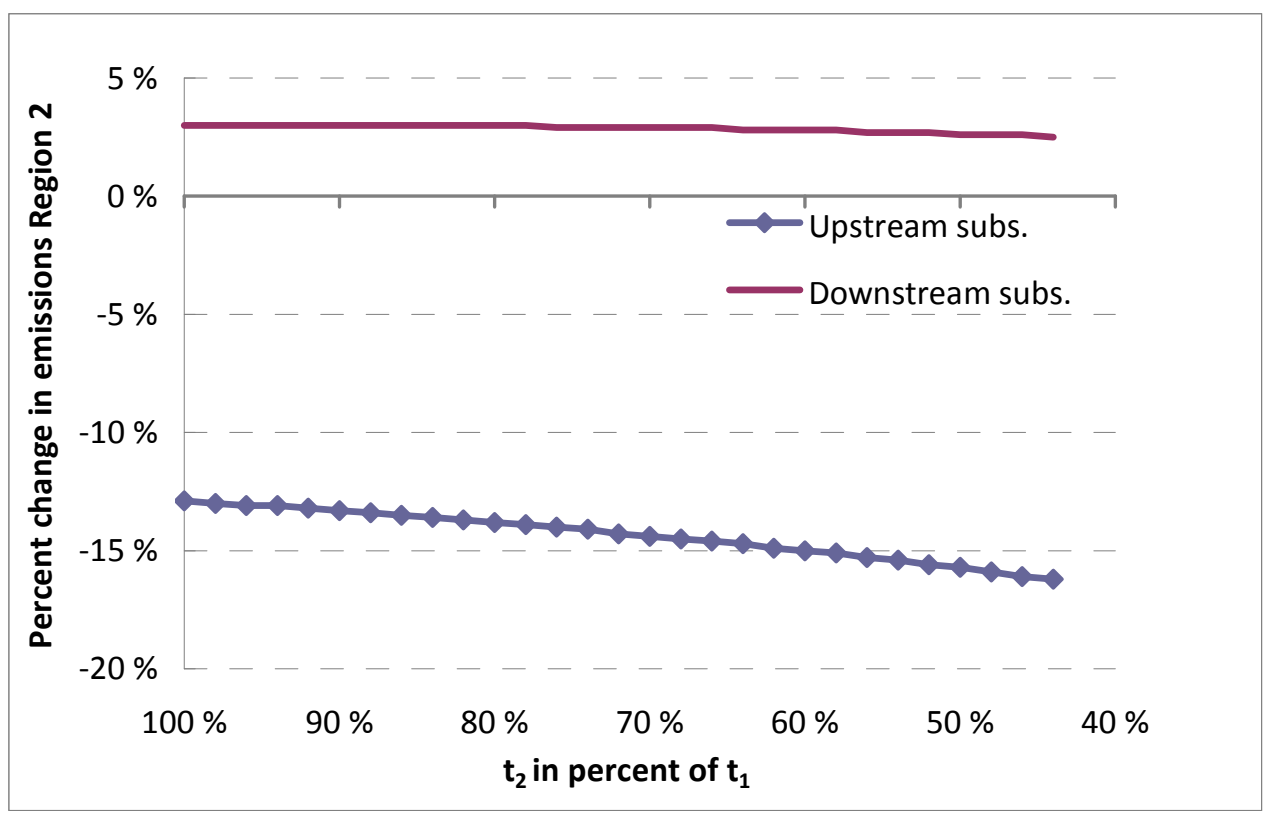

Note that for all $t_{2}$, the downstream subsidy increases emissions in Region 2 by around 3\% compared to our baseline. Since for lower tax rates, emissions from Region 2 are higher, the absolute emissions increases are larger for lower tax rates. Moreover, the upstream subsidy always reduces emissions abroad. The effect is significant; emissions are reduced by around $15 \%$.Note that even if we increase $m+n$ to 20 , there is still a positive leakage from the downstream subsidy.

Finally, we have looked at the welfare of Region 2. Technology policy need not be a beggarthy-neighbour policy in the case of emission leakages. For all configurations except 1-3, Region 2 also enjoys higher welfare even if Region 1 only maximizes its own welfare. 


\section{Discussion and conclusion}

In a context of carbon leakage concerns and a lack of political will to price carbon emissions to the full extent of the social costs, many countries have turned to abatement technology policies as both complements to and substitutes for emissions pricing. In this paper, we have considered to what degree abatement technology subsidies should be used, and whether they should be implemented downstream or upstream (or both). We conclude that a more robust recommendation can be made for upstream subsidies than for downstream subsidies. This is particularly the case from a strategic point of view for one region, but also in the case of maximizing global welfare when emission taxes differ across regions. The results are to a large extent driven by the fact that a downstream subsidy increases the world market price of abatement equipment, and that an upstream subsidy has the opposite effect. As a consequence, while both types can address some underprovision of abatement, downstream subsidies have ambiguous effects on emission leakage.

Do our assumption about Cournot competition upstream drive these results? Although we think that imperfect competition with capacity constraints best describes the relevant markets, we can show that all the qualitative results in Section 3 carry over if we rather assume perfect competition with increasing marginal costs. The same applies within the context of imperfect competition if we rather assume that upstream subsidies are provided as R\&D subsidies, and firms choose R\&D levels ahead of supply. ${ }^{5}$ Note also that in our simulations, the foreign firms left the market as $t_{2}$ became low compared to $t_{1}$. Still it was optimal to provide an upstream subsidy instead of a downstream subsidy due to the abatement technology price effect.

One may speculate whether upstream subsidies are more or less compatible with GATT law than

\footnotetext{
${ }^{5}$ An example of this is provided in an earlier version of this paper, see Fischer et al. (2012).
} 
downstream subsidies. On the one hand, countries could argue that they have chosen upstream subsidies over downstream subsidies since such subsidies will more likely reduce emissions both at home and abroad. On the other hand, Cosbey and Mavroidis (2014) argue that the WTO Agreement as it now stands does not consider environmental benefits as rationales for subsidies. Since both the downstream and the upstream subsidies involve financial contributions by the state to specific domestic recipients, they can in theory both be classified as domestic subsidies, which may be challenged under the WTO Agreement on Subsidies and Countervailing Measures. However, recent WTO case law may open up for exceptions with respect to pollution abatement technology. According to Cosbey and Mavroidis (2014), the Panel in the Ontario Renewable Energy case held that a subsidy aimed at creating a new market should not be equated to a subsidy aimed at providing advantages to existing producers in mature markets.

In order to analyze these questions, we have been forced to use explicit functional forms for both the emissions of the downstream industry and for production costs of the downstream industry. With more general forms, we would not be able to pin down the comparative statics effects of the two types of subsidies. We will, however, argue that the effects we have demonstrated above are more general than our model suggests. Increased demand for abatement equipment in one country spurred by an abatement subsidy will tend to increase the price of abatement equipment. This again will tend to reduce the use of abatement equipment in the region not having a similar incentive, which has negative consequences from a global point of view.

Some of our results might be thought to hinge on the assumption of fixed downstream demand. We have therefore solved the model for linear demand downstream, and most results go through; in particular, the result that the price on abatement technology increases in the downstream subsidy 
and decreases in the upstream subsidy remains. ${ }^{6}$ One possible exception is the effect on foreign emissions of an upstream subsidy. With linear demand downstream, a certain emissions rebound effect can occur as costs fall and total downstream production increases. However, this rebound effect almost never dominates the primary effect of lowering emissions. Numerical simulations with linear demand and initial demand elasticity of -0.75 give the same qualitative conclusions as with fixed demand.

We have only analyzed unilateral technology policy, and it would clearly be interesting to look at a Nash-equilibrium in technology policies. For $\eta_{1}=\gamma_{1}=0$, Region 2 would have the same incentives as Region 1, and there might exist a Nash-equilibrium with positive upstream subsidies in both regions. If regions are similar, they might both benefit from this due to the increased use of abatement technology in both regions (see end of the numerical section above). Thus, as opposed to strategic trade policy, subsidizing production of abatement technology may not qualify as a Prisoners Dilemma.

We have also treated the emission tax rates as exogenous. In case the emissions in question comes from many sources, such as green house gasses, the emission tax rates will not be decided with regards to the industry in our model alone. On the contrary, technology policy can be tailormade to separate industries and their abatement technology needs. In case emissions are special for the industry we are looking at, it would be interesting to make emission taxes endogenous. If one believes that governments can adjust technology policy more easily than emission taxes, one may also assume that taxes are set before technology policy. Do regions then set the tax high because you know that this commits them to a tough technology policy, or do regions set the tax low in

\footnotetext{
${ }^{6}$ A short note covering this case can be obtained from the authors upon request. The derivations are much more involved, and we therefore chose to keep the more simple model in the paper.
} 
order to make regions commit to a tough technology policy from which they also will benefit? This might be an interesting avenue of future research.

Intuition from this model can also be used to speculate on the effectiveness of alternative measures. For example, how might upstream abatement subsidies compare with output-based allocation of emission quotas, which is used in the EU Emission Trading System? Output-based allocation of emission quotas work in very much the same way as a combination of an emission price and an output subsidy, which will tend to increase downstream demand for cleaner technology (compared to emission pricing only). ${ }^{7}$ Thus, output-based allocation will have no direct effect on foreign industries' abatement technology choices, and will likely not give local upstream abatement technology firms an advantage. Moreover, we can show that in our model they increase abatement technology prices, and may therefore fail to reduce emissions leakage.

\section{References}

[1] Brander J. and B. Spencer, Export Subsidies and International Market Share Rivalry, J. Internat. Econom. 18, p. 83-100 (1985).

[2] Böhringer, C., Fischer, C., Rosendahl, K.E. 2010. The Global Effects of Subglobal Climate Policies, The B.E. Journal of Economic Analysis \& Policy 10(2) (Symposium): Article 13.

[3] Copenhagen Accord. 2009. http://unfccc.int/resource/docs/2009/cop15/eng/107.pdf

[4] Cosbey A. \& P. C. Mavroidis (2014): A Turquoise Mess: Green Subsidies, Blue Industrial Policy and Renewable Energy: the Case for Redrafting the Subsidies Agreement of the WTO, unpublished manuscript.

[5] David, M. and B. Sinclair-Desgagné. 2010. Pollution Abatement Subsidies and the Eco-

\footnotetext{
${ }^{7}$ From (1) we see that abatement demand increases when output increases. In addition you may have an additional effect from increased permit prices.
} 
Industry, Environ Resource Econ 45:271-282

[6] Demailly D. and P. Quirion 2006. CO2 abatement, competitiveness and leakage in the European cement industry under the EU ETS: Grandfathering vs. output-based allocation, Climate Policy 6(1): 93-113.

[7] Fischer, C. and A.K. Fox. 2012. Comparing Policies to Combat Emissions Leakage: Border Tax Adjustments versus Rebates. Journal of Environmental Economics and Management. 64 (2): 199-216 (September).

[8] Fischer, C., Greaker, M. and K. E. Rosendahl. 2012. Emissions leakage and subsidies for pollution abatement. Pay the polluter or the supplier of the remedy? Discussion Papers 708, Statistics Norway.

[9] Fredriksson, P.G. 1998. Environmental policy choice: Pollution abatement subsidies, Resource Energy Econ 20:51-63

[10] Golombek, R. and M. Hoel. 2004. Unilateral Emissions Reductions and Cross-Country Technology Spillovers. Advances in Economic Analysis 8 Policy 4 (2): Article 3.

[11] Greaker, M. and K. E. Rosendahl. 2008. Environmental policy with upstream pollution abatement technology firms, J. Environ. Econom. Management 56, pp. 246-259.

[12] Greaker, M. 2006. Eco-labels, Trade and Protectionism, Environmental and Resource Economics 33, p. 1-37.

[13] Hoel, M. 1996. Should a carbon tax be differentiated across sectors? Journal of Public Economics 1996 p. 17-32.

[14] Laffont, J.-J. and J. Tirole, 1996, Pollution permits and compliance strategies. Journal of Public Economics 62, 85-125.

[15] Lerner, A. P. 1972. Pollution abatement subsidies, American Economic Review. 62 (5): 1009- 
1010.

[16] Millock, K. and C. Nauges. 2006. Ex Post Evaluation of an Earmarked Tax on Air Pollution, Land Economics 82, 68-84.

[17] Mæstad 1998. On the efficiency of Green Trade Policy. Environmental and Resource Economics 11, p. 1-18.

[18] Mæstad 2001. Efficient Climate Policy with Internationally Mobile Firms, Environmental and Resource Economics 19, p. 267-284.

[19] Meade, James E. 1955. The Theory of Customs Unions. Amsterdam: North-Holland.

[20] Requate T. 2005. Timing and Commitment of Environmental Policy, Adoption of New Technology, and Repercussions on R\&D, Environmental and resource Economics 31, p. 175-199.

[21] Rosendahl, K.E. and H. Storrøsten (2011): Output-based allocation and investment in clean technologies, Discussion Papers No. 644, Statistics Norway.

[22] World Trade Organization 2011. Harnessing trade for sustainable development and a green economy, Geneva, Switzerland.

Derivation of the reduced form cost function in (3):

$$
\begin{aligned}
C_{i} & =\frac{q_{i}^{2}}{2}+\frac{t_{i}}{2}\left(q_{i}+\frac{\left(w-\eta_{i}\right)\left(t_{i}+w-\eta_{i}\right)}{t_{i}^{2}}\right)+\left(w-\eta_{i}\right)\left(q_{i}-\frac{t_{i}+w-\eta_{i}}{t_{i}}\right) \\
& =\frac{q_{i}^{2}}{2}+\frac{t_{i}}{2} q_{i}+\frac{1}{2} \frac{\left(w-\eta_{i}\right)\left(t_{i}+w-\eta_{i}\right)}{t_{i}}+\left(w-\eta_{i}\right) q_{i}-\frac{\left(w-\eta_{i}\right)\left(t_{i}+w-\eta_{i}\right)}{t_{i}} \\
& =\frac{q_{i}^{2}}{2}+\left(\frac{t_{i}}{2}+w-\eta_{i}\right) q_{i}-\frac{1}{2} \frac{\left(w-\eta_{i}\right)\left(t_{i}+w-\eta_{i}\right)}{t_{i}}
\end{aligned}
$$

Derivations of the Nash equilibrium upstream (equations (7) and (8)): 
The two upstream firms maximixe:

$$
\left[\frac{t_{1} t_{2}}{t_{1}+t_{2}}\left(Q+\frac{\eta_{1}}{t_{1}}+\frac{\eta_{2}}{t_{2}}-2-y_{1}-y_{2}\right)-\left(\rho-\gamma_{i}\right)\right] y_{i}
$$

where we have inserted from (6) and replaced $x_{1}+x_{2}$ by $y_{1}+y_{2}$.

First order conditions are:

$$
\begin{aligned}
& Q+\frac{\eta_{1}}{t_{1}}+\frac{\eta_{2}}{t_{2}}-2-2 y_{1}-y_{2}-\frac{t_{1}+t_{2}}{t_{1} t_{2}}\left(\rho-\gamma_{1}\right)=0 \\
& Q+\frac{\eta_{1}}{t_{1}}+\frac{\eta_{2}}{t_{2}}-2-y_{1}-2 y_{2}-\frac{t_{1}+t_{2}}{t_{1} t_{2}}\left(\rho-\gamma_{2}\right)=0
\end{aligned}
$$

The solution is:

$$
\begin{aligned}
& y_{1}=\frac{Q-2}{3}+\frac{\eta_{1}}{3 t_{1}}+\frac{\eta_{2}}{3 t_{2}}+\left(2 \gamma_{1}-\gamma_{2}-\rho\right) \frac{t_{1}+t_{2}}{3 t_{1} t_{2}} \\
& y_{2}=\frac{Q-2}{3}+\frac{\eta_{1}}{3 t_{1}}+\frac{\eta_{2}}{3 t_{2}}+\left(2 \gamma_{2}-\gamma_{1}-\rho\right) \frac{t_{1}+t_{2}}{3 t_{1} t_{2}}
\end{aligned}
$$

By inserting the expressions for $y_{1}$ and $y_{2}$ into (6), we get:

$$
w=\frac{t_{1} t_{2}}{t_{1}+t_{2}}\left(\frac{Q-2}{3}+\frac{\eta_{1}}{3 t_{1}}+\frac{\eta_{2}}{3 t_{2}}\right)-\frac{\gamma_{1}+\gamma_{2}-2 \rho}{3}
$$

Derivations of leakage effects (equations (9)-(11)): 


$$
\begin{aligned}
\frac{d e_{2}}{d t_{1}} & =\frac{1}{2} \frac{d q_{2}}{d t_{1}}+\frac{1}{2 t_{2}^{2}}\left(t_{2}+w-\eta_{2}+w-\eta_{2}\right) \frac{d w}{d t_{1}} \\
& =\frac{1}{8}+\frac{1}{2 t_{2}^{2}}\left(t_{2}+2 w-2 \eta_{2}\right) \frac{\left(t_{2}\right)^{2}}{\left(t_{1}+t_{2}\right)^{2}}\left(\frac{Q-2}{3}+\frac{\eta_{2}-\eta_{1}}{3 t_{2}}\right) \\
& =\frac{1}{8}+\frac{\left(t_{2} / 2+w-\eta_{2}\right)}{\left(t_{1}+t_{2}\right)^{2}}\left(\frac{Q-2}{3}+\frac{\eta_{2}-\eta_{1}}{3 t_{2}}\right)
\end{aligned}
$$

$$
\begin{aligned}
\frac{\partial e_{2}}{\partial \eta_{1}} & =\frac{1}{2} \frac{d q_{2}}{d \eta_{1}}+\frac{1}{2 t_{2}^{2}}\left(t_{2}+w-\eta_{2}+w-\eta_{2}\right) \frac{d w}{d \eta_{1}} \\
& =-\frac{1}{4}+\frac{1}{2 t_{2}^{2}}\left(t_{2}+w-\eta_{2}+w-\eta_{2}\right) \frac{t_{1} t_{2}}{t_{1}+t_{2}} \frac{1}{3 t_{1}} \\
& =\frac{t_{2} / 2+w-\eta_{2}}{3 t_{2}\left(t_{1}+t_{2}\right)}-\frac{1}{4}
\end{aligned}
$$

$$
\begin{aligned}
\frac{\partial e_{2}}{\partial \gamma_{1}} & =\frac{1}{2} \frac{d q_{2}}{d \gamma_{1}}+\frac{1}{2 t_{2}^{2}}\left(t_{2}+w-\eta_{2}+w-\eta_{2}\right) \frac{d w}{d \gamma_{1}} \\
& =\frac{1}{2 t_{2}^{2}}\left(t_{2}+w-\eta_{2}+w-\eta_{2}\right) \frac{(-1)}{3} \\
& =-\frac{t_{2} / 2+w-\eta_{2}}{3\left(t_{2}\right)^{2}}
\end{aligned}
$$

Derivations of global welfare cost effects (equations (16) and (17)):

Inserting from (1), (2) and (5) into (15) yields: 


$$
\begin{aligned}
T C= & \frac{\left(Q+\left(t_{2}-t_{1}\right) / 2+\eta_{1}-\eta_{2}\right)^{2}}{8}+\frac{\left(Q+\left(t_{1}-t_{2}\right) / 2+\eta_{2}-\eta_{1}\right)^{2}}{8} \\
& +\rho\left(Q-\frac{w+t_{1}-\eta_{1}}{t_{1}}-\frac{w+t_{2}-\eta_{2}}{t_{2}}\right) \\
& +\left(t_{1}+t_{2}\right)\left[Q / 2+\frac{\left(w-\eta_{1}\right)\left(w+t_{1}-\eta_{1}\right)}{2\left(t_{1}\right)^{2}}+\frac{\left(w-\eta_{2}\right)\left(w+t_{2}-\eta_{2}\right)}{2\left(t_{2}\right)^{2}}\right]
\end{aligned}
$$

Differentiating with respect to $\eta_{1}$ and rearranging gives:

$$
\begin{gathered}
\frac{d T C}{d \eta_{1}}=\frac{t_{2}-t_{1}}{4}+\frac{\eta_{1}-\eta_{2}}{2}-\frac{t_{1}+t_{2}}{\left(t_{1}\right)^{2}}\left[w-\eta_{1}+\frac{t_{1}}{2}-\frac{t_{1}}{t_{1}+t_{2}} \rho\right]\left[1-\frac{d w}{d \eta_{1}}\right] \\
+\frac{t_{1}+t_{2}}{\left(t_{2}\right)^{2}}\left[w-\eta_{2}+\frac{t_{2}}{2}-\frac{t_{2}}{t_{1}+t_{2}} \rho\right] \frac{d w}{d \eta_{1}}=0
\end{gathered}
$$

Differentiating with respect to $\gamma_{1}$ and rearranging gives:

$$
\frac{d T C}{d \gamma_{1}}=\frac{t_{1}+t_{2}}{\left(t_{1}\right)^{2}}\left[w+\frac{t_{1}}{2}-\eta_{1}-\frac{t_{1}}{t_{1}+t_{2}} \rho\right] \frac{d w}{d \gamma_{1}}+\frac{t_{1}+t_{2}}{\left(t_{2}\right)^{2}}\left[w+\frac{t_{2}}{2}-\eta_{2}-\frac{t_{2}}{t_{1}+t_{2}} \rho\right] \frac{d w}{d \gamma_{1}}=0
$$

\section{Derivations of the reduced form of $\gamma_{1}$ :}

By differentiating (8) with respect to $\gamma_{1}$, inserting into (17) and then rearranging, we get:

$$
w=\frac{\left(t_{2}\right)^{2} \eta_{1}+\left(t_{1}\right)^{2} \eta_{2}-\left(t_{1}\left(t_{2}\right)^{2}+\left(t_{1}\right)^{2} t_{2}\right) / 2+\left[\frac{\left(t_{1}\right)^{2} t_{2}+t_{1}\left(t_{2}\right)^{2}}{t_{1}+t_{2}}\right] \rho}{\left(t_{1}\right)^{2}+\left(t_{2}\right)^{2}}
$$


Inserting this into (8) and rearranging gives

$\gamma_{1}=3\left[\frac{2 \rho}{3}+\frac{t_{1} t_{2}}{t_{1}+t_{2}}\left(\frac{Q-2}{3}+\frac{\eta_{1}}{3 t_{1}}+\frac{\eta_{2}}{3 t_{2}}\right)-\frac{\left(t_{2}\right)^{2} \eta_{1}+\left(t_{1}\right)^{2} \eta_{2}-\left(t_{1}\left(t_{2}\right)^{2}+\left(t_{1}\right)^{2} t_{2}\right) / 2+\left[\frac{\left(t_{1}\right)^{2} t_{2}+t_{1}\left(t_{2}\right)^{2}}{t_{1}+t_{2}}\right] \rho}{\left(t_{1}\right)^{2}+\left(t_{2}\right)^{2}}\right]-\gamma_{2}$
$\gamma_{1}=2 \rho-\gamma_{2}+\frac{3 t_{1} t_{2}}{t_{1}+t_{2}}\left(\frac{Q-2}{3}+\frac{\eta_{1}}{3 t_{1}}+\frac{\eta_{2}}{3 t_{2}}\right)-\frac{3\left(t_{2}\right)^{2} \eta_{1}+3\left(t_{1}\right)^{2} \eta_{2}-3\left(t_{1}\left(t_{2}\right)^{2}+\left(t_{1}\right)^{2} t_{2}\right) / 2+3\left[\frac{\left(t_{1}\right)^{2} t_{2}+t_{1}\left(t_{2}\right)^{2}}{t_{1}+t_{2}}\right] \rho}{\left(t_{1}\right)^{2}+\left(t_{2}\right)^{2}}$

The Cournot equilibrium with $\mathbf{n}+\mathbf{m}$ upstream firms for the numerical example:

In equilibrium $m y_{1}+n y_{2}=x_{1}+x_{2}$. All firms maximize profits: $\left[w-\rho+\gamma_{i}\right] y_{i}$. The Nashequilibrium outputs and price on abatement technology:

$$
\begin{aligned}
& y_{1}=\frac{1}{m+n+1}\left[Q-2+\frac{\eta_{1}}{t_{1}}+\frac{\eta_{2}}{t_{2}}-\frac{t_{1}+t_{2}}{t_{1} t_{2}}\left[\rho-(n+1) \gamma_{1}+n \gamma_{2}\right]\right] \\
& y_{2}=\frac{1}{m+n+1}\left[Q-2+\frac{\eta_{1}}{t_{1}}+\frac{\eta_{2}}{t_{2}}-\frac{t_{1}+t_{2}}{t_{1} t_{2}}\left[\rho+m \gamma_{1}-(m+1) \gamma_{2}\right]\right]
\end{aligned}
$$

For the total supply of abatement equipment we have:

$$
x_{1}+x_{2}=\frac{m+n}{m+n+1}\left[Q-2+\frac{\eta_{1}}{t_{1}}+\frac{\eta_{2}}{t_{2}}\right]-\frac{t_{1}+t_{2}}{t_{1} t_{2}} \frac{(m+n) \rho-m \gamma_{1}-n \gamma_{2}}{m+n+1}
$$

from which we obtain the upstream price:

$$
w=\frac{t_{1} t_{2}}{\left(t_{1}+t_{2}\right)(m+n+1)}\left[Q-2+\frac{\eta_{1}}{t_{1}}+\frac{\eta_{2}}{t_{2}}\right]+\frac{(m+n) \rho-m \gamma_{1}-n \gamma_{2}}{m+n+1}
$$

